\title{
A quantitative approach to the concept of concrete repair compatibility
}

B. Bissonnette

CRIB, Department of Civil Engineering, Laval University, Quebec City, QC, Canada

F. Modjabi-Sangnier

$S N C$-Lavalin, Montreal (QC), Canada, QC, Canada

L. Courard

GeMMe Building Materials, ArGEnCo Department, University of Liège, Liège, Belgium

A. Garbacz

Warsaw University of Technology, Warsaw, Poland

A.M. Vaysburd

Vaycon Consulting, Baltimore, MD, U.S.A.

ABSTRACT: The work reported in this paper is part of a wider research program intended to provide the repair industry with improved fundamental knowledge to implement rational design methods and rules for repairs. In that regard, there is a strong need to study the fundamental relationships and parameters that underlie the repair compatibility concepts, in particular those relating to dimensional compatibility. In the first part of the paper, classical formulas derived for thick cylindrical specimens were used to analyze the tensile stress buildup in annular restrained shrinkage test specimens, taking into account the restraining conditions of the investigated ring test method and the individual concrete properties/phenomena determined experimentally (elastic modulus, creep coefficient, drying shrinkage deformation). By comparing the ring test results with the calculated tensile stresses, the validity and accuracy of the theoretical approach could be appraised. A quantitative approach for the evaluation of the performance of concrete repair in terms of dimensional compatibility was then developed. Derived from the basic strain balance approach (ratio between the total deformability in tension and the drying shrinkage deformation), a parameter referred to as dimensional compatibility index (CI) was introduced in order to analyze the evolution of dimensional compatibility as a function of time for a given concrete mixture, taking into account the actual degree of restraint in the element. Compatibility index evolution curves were calculated for various repair concrete mixtures in order to highlight material behavior relating to composition parameters and temperature. As it requires the evaluation of a limited number of individual properties that are for most readily available (i.e. strength, elastic modulus, shrinkage), the compatibility index expressed in terms of deformation carries a lot of potential as a relatively simple and convenient analytical tool for assessing the cracking sensitivity of concrete repair materials. Overall, it can be stated that a good correlation was found between the ring test results and the tensile stress values calculated based on individual concrete properties / phenomena and that the proposed calculation method lays ground for evaluating quantitatively the dimensional compatibility of repair materials and defining suitable performance criteria.

\section{INTRODUCTION AND SCOPE}

In the field of civil engineering, repair and rehabilitation have drawn significant attention in the recent years. Even though engineers have been repairing deteriorated structures for many years now, the rate of unsuccessful concrete repairs remains unacceptably high. Because of the lack of knowledge gained on the influence of certain fundamental parameters, the achievement of durable repairs is reduced in some circumstances to merely a "hit or miss" process.

The aim of concrete repairs is to prolong the useful service life of an existing structure, to restore its load-carrying capacity and stiffness, and/or to strengthen its members. A prerequisite to achieve adequate composite action is lasting bond between the existing substrate and the newly-cast material. In this respect, compatibility between the repair material and the existing concrete is of critical importance. In fact, the level of compatibility will generally determine whether a repair project is a success or a failure, and whether or not a repaired structure is durable.

The importance of dimensional compatibility between existing concrete and repair materials has been addressed conceptually by various authors (Emberson \& Mays, 1990; Plum, 1990; Pigeon \& Saucier, 1990; Emmons \& Vaysburd, 1993, 1995; Cusson, 1995; Morgan, 1996; Pigeon \& Bissonnette, 
1999; Vaysburd et al., 2015). Experimental studies have then confirmed the significant role played by creep in the global dimensional balance and the risk for cracking, especially shrinkage-induced cracking (Morgan, 1996; Pigeon \& Bissonnette, 1999; See et al., 2003). One of the most significant findings is that tensile creep appears to be more sensitive than shrinkage to certain mix design parameters (Pigeon \& Bissonnette, 1999), which opens up the possibility of designing materials in view of optimizing their creep to shrinkage ratio. Moreover, a correlation between tensile creep and shrinkage was observed, a trend that could be taken advantage of in both calculations and the identification of performance criteria for repair materials.

One of the main challenges to be faced now lies in evaluating quantitatively compatibility and determining what it requires under given circumstances (characteristics of the structure to be repaired and the environment). So far, even though the concepts have been described in great detail by a number of authors, there are still no reliable criteria or design rules, fundamental or empirical, available to engineers. Some interesting empirical approaches have been suggested, for instance the stress performance margin (Marosszeky, 1992), which consists of an index meant to compare the cracking sensitivity of various repair materials, or the USACE's tentative Performance criteria for repair materials (Emmons et al., 1993), which summarizes the limit values a material should exhibit in selected test procedures for shrinkage and cracking. Those indices and criteria are certainly a step in the right direction, but they lack a fundamental basis, as they do not address explicitly compatibility.

Besides, for the compatibility approach to become accessible to the industry, simple and reliable characterization tests are needed. Various test procedures (ring test, beam curling test, box test) have been developed in recent years for the evaluation of the cracking sensitivity of repair materials (Morency et al., 2005). Some of those so-called performance tests could become key tools for the identification of performance criteria, provided that clear relationships with both the basic material properties and the composite repair behavior are established.

Recently, laboratory and field studies have demonstrated the potential and benefits of different innovative materials or products like shrinkagecompensating concrete, self-consolidating concrete, and shrinkage-reducing admixtures. In order to perform successful repairs with such materials on a consistent basis (optimization and robustness of repair materials), it is needed to quantify their key compatibility properties and determine what is the sensitivity of those properties to the mixture composition and constituents.

\section{OBJECTIVES AND PROPOSED APPROACH}

The work reported in this paper is part of a wider research program intended to provide the repair industry with improved fundamental knowledge to implement rational design methods and rules for repairs. In that regard, there is a strong need to quantify and correlate the relevant aspects of dimensional compatibility in order to consistently achieve repair works that do not undergo harmful cracking and loss of bond with time. Ultimately, the objective is to provide the industry with performance criteria and guidelines.

More specifically, this paper summarizes the work achieved to relate quantitatively the individual dimensional compatibility-related properties (notably elastic properties, creep, drying shrinkage) to the corresponding stress and strain values recorded in an annular restrained shrinkage test, commonly referred to as the ring test. In the first part of the program, classical formulas derived for thick cylindrical specimens were used to analyze the tensile stress buildup in restrained shrinkage test specimens. A quantitative approach for the evaluation of concrete repair with a single dimensional compatibility parameter, the compatibility index, was then developed. Compatibility index evolution curves were finally calculated for a range of repair concrete mixtures in order to validate the approach and highlight material behavior relating to composition parameters and temperature.

\section{MECHANICAL ANALYSIS OF THE RING TEST EXPERIMENT}

The dimensional balance inside a repair is governed by the volume changes and mechanical properties of the repair material, together with the level of restraint provided by the existing structure. Thus, in order to evaluate the restrained shrinkage cracking sensitivity of materials, the analysis must take into account the combined effect of these properties and phenomena.

This complex task can be simplified by addressing the evolution of the stress state in a simple restrained-shrinkage element such as that used in ringtype tests (Fig. 1). In this type of experiment, the tested material is cast around a rigid steel ring, which opposes the shrinkage deformations that occurs after setting and curing. The actual level of restraint provided by the steel ring depends on the respective geometrical and material stiffnesses of the two annular bodies (steel and concrete rings) in contact with each other. The internal stresses that develop in the system are determined by monitoring the deformations in the steel ring with strain gages. 


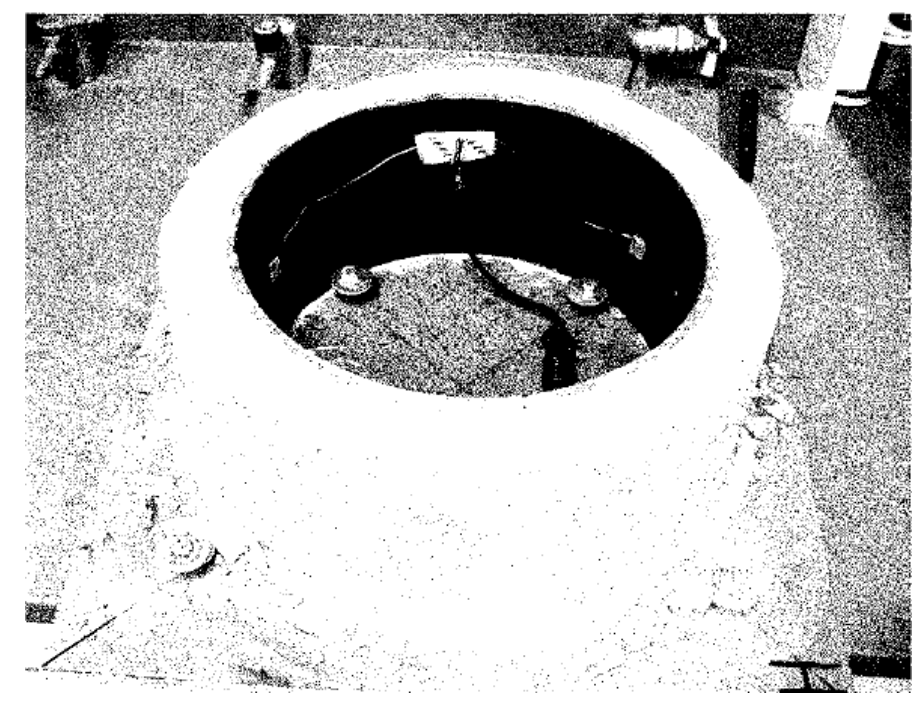

Figure 1. Example of ring test specimen (ASTM C1581) to study the restrained-shrinkage behavior of mortar and concrete mixtures

On the basis of the theory of elasticity and a given geometry of the annular test device, it is possible to calculate the circumferential stresses developing in the annular concrete sample due to drying shrinkage restrained by the inner steel ring (Fig. 2). Classical formulas derived for thick cylindrical specimens were used to estimate the tensile stress buildup in restrained shrinkage test specimens, taking into account the individual concrete properties and phenomena determined experimentally (drying shrinkage deformation, creep coefficient, elastic modulus), as well as the restraining conditions of the investigated ring test specimen. A similar approach has been proposed by Hossain \& Weiss (2006). Although the principle of superposition of deformations is not rigorously valid in cement-based materials, mostly due to ageing effects, from a design standpoint, the accuracy of the quantitative evaluation it provides is satisfactory enough from an repair design engineering standpoint, as demonstrated by its extensive use in handbooks and building codes.

based on the average stresses. The evolution of the average shrinkage-induced stress $\left(\sigma_{c}\right.$ avg. $)$ over time can be calculated with equation 1 , where $\varepsilon_{f s}$ is the concrete free shrinkage, $E_{c}$ and $E_{s}$ are the elastic moduli of concrete and steel, $\phi_{c}$ is the creep coefficient of concrete, $v_{c}$ and $v_{s}$ are the Poisson's ratios of concrete and steel, and $a, b$, and $c$, are the internal, interfacial and external radii of the composite steelconcrete ring specimen.

$$
\sigma_{c \text { avg. }}(t)=\frac{b(b+c)}{c^{2}-b^{2}} \frac{\varepsilon_{f s}(t)}{\left[\frac{1}{E_{s}}\left(\frac{b^{2}+a^{2}}{b^{2}-a^{2}}+v_{s}\right)+\frac{1+\phi_{c}(t)}{E_{c}(t)}\left(\frac{b^{2}+c^{2}}{c^{2}-b^{2}}-v_{c}\right)\right]}
$$

By comparing the ring test results with the calculated tensile stresses, the validity and accuracy of the theoretical approach could be appraised.

Figure 3 shows ring test results obtained for an ordinary repair concrete (OPC), together with two self-compacting repair concrete mixtures produced with a slag-based ternary binder (SCC-ST) and a flyash-based ternary binder (SCC-FT) respectively. On each diagram, the calculated theoretical stress evolution with and without stress relaxation (lower and upper solid red lines respectively) and the experimental stress recorded over time in the ring test (solid blue line) are presented together with the corresponding tensile strength evolution curve (black line).

The pink areas between the red lines on the graphs of Figure 3 correspond to the theoretical stress relaxation potential of the concrete. By comparing the shaded areas in the two diagrams (= area between the tensile strength curve and the lower red line), it can be concluded that the OPC and SCC-ST mixtures are much less sensitive to shrinkage cracking than the SCC-FT mixture. In fact, in diagram c), both the theoretical tensile stress (including relaxation) and the recorded stress curves reach or get close to the tensile strength curve quite rapidly, whereas in diagrams a) and b), the recorded stress remains much lower, coinciding more or less with the relaxed stress curves.

Overall, a good correlation was found between the ring test results and the tensile stress values calculated based on individual concrete properties / phenomena. The level of correlation was particularly high when the test specimens (beams, rings) were partially sealed such as to obtain the

Figure 2. Basic analysis of the restrained shrinkage test specimen (mechanical equilibrium) and geometrical parameters.

While the actual deformation and stress gradients across the thickness of the specimens are considered in the calculations, the analysis of the results is same drying surface / volume ratio $(\mathrm{S} / \mathrm{V})$ in the various experiments. Based on the collected data and observations, it can be asserted that the calculation method that was developed provides a good basis for analyzing quantitatively the dimensional compatibility of repair materials. 


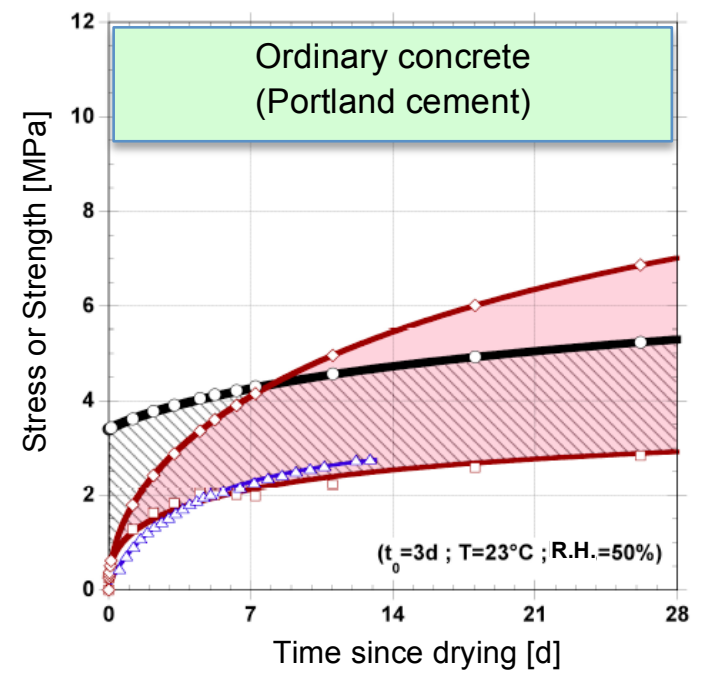

a) Ordinary repair concrete mixture (OPC)

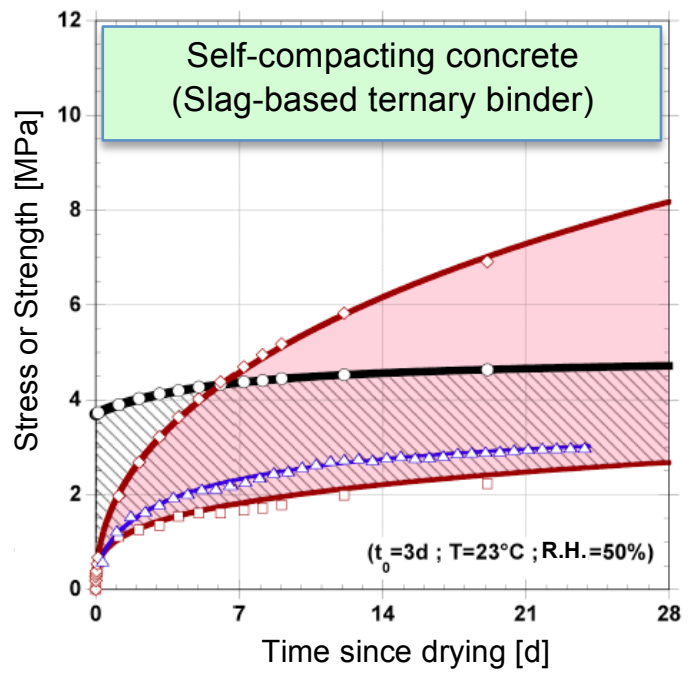

b) Self-compacting repair concrete mixture with slag and naphthalene-based superplasticizing admixture (SCC-ST)

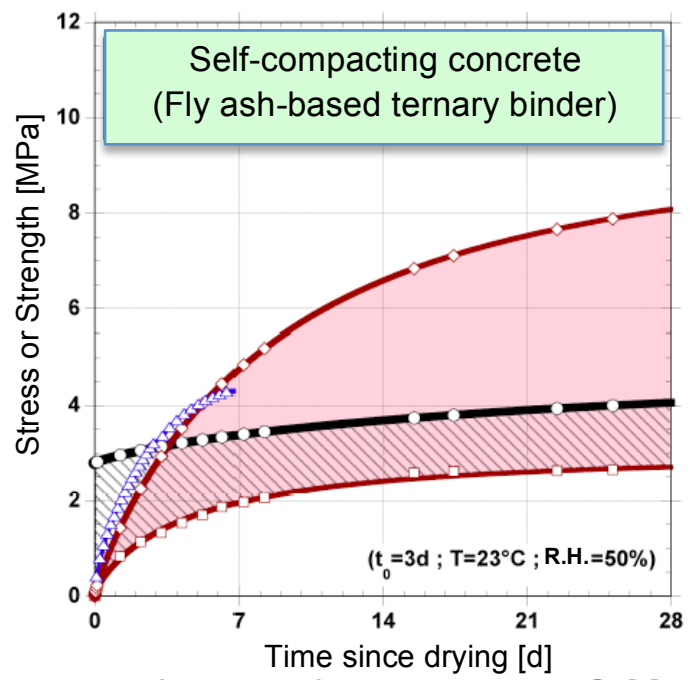

c) Self-compacting repair concrete mixture with fly ash and polycarboxylate-based superplasticizing admixture (SCC-FT)

Figure 3. Comparative development of recorded and theoretical tensile stresses in AASHTO PP34 ring tests for a reference repair concrete (OPC) and two self-compacting repair concrete mixtures (SCC-ST, SCC-FT) exposed to drying at $50 \%$ R.H. at the age of 3 days (note: solid blue line: stress recorded in the ring; lower and upper solid red lines: theoretical average concrete stress, with and without stress relaxation respectively; solid black line: tensile strength of the concrete).

\section{QUANTITATIVE ASSESSMENT OF DIMENSIONAL COMPATIBILITY}

The aforementioned mathematical formulas were further used to define a quantitative parameter for the evaluation of the performance of concrete repair in terms of dimensional compatibility. Derived from the basic strain balance approach (ratio between the total deformability in tension and the drying shrinkage deformation), the dimensional compatibility index (CI) was thus introduced in order to analyze the evolution of dimensional compatibility as a function of time for a given concrete mixture, taking into account the actual degree of restraint in the test specimen.

The dimensional compatibility index can be expressed in terms of deformation, thus allowing to relate explicitly to the various individual properties and phenomena involved in the material's response in restrained shrinkage conditions (strength, elastic modulus, creep, drying shrinkage), as well as to the degree of restriction of the element. For the latter, constants are calculated, based upon the respective geometry and mechanical properties (Poisson's ratio) of both the restraining device and the test specimen. The time-dependent expression takes the following general form, where $f_{t}$ is the concrete tensile strength, $\alpha_{r}$ is the instantaneous elastic restraint, and $\alpha_{r}^{\prime}$ is the creep-dependent restraint:

$$
\begin{gathered}
\text { C.I. }(t)=\frac{\left[\frac{f_{t}(t)}{E_{c}(t)}+\phi_{c}(t) \varepsilon_{f s}(t) \alpha_{r}(t) \cdot \frac{C_{c}}{C_{g}} \alpha_{r}^{\prime}(t)\right]}{\varepsilon_{f s}(t) \alpha_{r}(t)} \\
C_{g}=\frac{b(b+c)}{c^{2}-b^{2}} \quad C_{c}=\frac{b^{2}+c^{2}}{c^{2}-b^{2}}-v_{c} \quad C_{s}=\frac{b^{2}+a^{2}}{b^{2}-a^{2}}+v_{s} \\
\alpha_{r}(t)=\frac{C_{g}}{\left(\frac{C_{s}}{E_{s}}+\frac{C_{c}}{E_{c}(t)}\right) E_{c}(t)} \\
\alpha_{r}^{\prime}(t)=\frac{C_{g}}{\left(\frac{C_{s}}{E_{s}}+\frac{C_{c}\left(1+\phi_{c}(t)\right)}{E_{c}(t)}\right) E_{c}(t)}
\end{gathered}
$$

As it requires the evaluation of individual properties that for most are readily available (i.e. strength, elastic modulus, and drying shrinkage), the compatibility index carries much potential as a relatively simple and convenient analytical tool for assessing the cracking potential of concrete repair materials.

The CI parameter can alternatively be expressed in terms of stress. The compatibility index is then calculated as the ratio between the sum of the tensile strength $\left(f_{t}\right)$ and total stress relaxation $\left(\Delta \sigma_{\text {relaxation }}\right)$ in given restraining conditions, and the averaged elastic stress $\left(\sigma_{\text {elastic }}\right)$ induced by restrained drying shrinkage. 


\section{EXAMPLES OF MATERIAL TENDENCIES REVEALED WITH THE COMPATIBILITY INDEX}

The CI evolution allows to assessing whether the concrete can withstand shrinkage-induced cracking over time, taking into account the various phenomena involved and their complex interaction. Compatibility index evolution curves were calculated for different repair concrete mixtures in order to highlight characteristic material behavior relating to specific composition parameters and temperature (ModjabiSangnier, 2010).

The diagram presented in Figure 4 shows the evolution of this index for the same three concrete mixtures tested in the ring experiments (Fig. 3). Typically high at early age, the CI value is observed to decrease gradually with the ageing process, with quite steep decreasing rates in the first few days. During the drying period considered ( 0 to $28 \mathrm{~d}$ ), the CI values of the shrinkage-compensating (SCC) mixture produced with a slag-based ternary binder and the reference ordinary concrete (OPC) mixture are significantly higher than those determined for the fly-ash-based SCC mixture, especially in the first two weeks of drying. In other words, the two former mixtures seem to exhibit much more early-age dimensional compatibility than the SCC-TF repair mixture. The ring tests stress development curves on the diagrams of Figure 3 reveals show good agreement with the trends revealed by the CI curves. As a matter of fact, the rapid increase in tensile stress recorded for the SCC-TF rings is consistent with the much steeper decreasing rate of the CI value observed in Figure 4.

As already indicated, the CI curves can be used to compare the compatibility of different concrete mixtures and to identify specific material tendencies. In a recent investigation by Modjabi-Sangnier (2010), the comparison of results for a range of repair mixtures and curing conditions has shown that dimensional compatibility is very sensitive to certain composition variables and to temperature in the early stages of hydration. For instance, test results generated in this study remarkably show that a given binder / plasticizer agent combination can yield quite different conclusions depending on the curing temperatures. While some combinations exhibit more interesting characteristics at low curing temperatures with respect to compatibility and the cracking risk, others show exactly the opposite, as shown on the graph of Figure 5.

Based upon comprehensive experimental work by Modjabi-Sangnier (2010), it can be concluded that the composition parameters and the thermal conditions during the setting and hardening period may influence the susceptibility to cracking of a cementitious material undergoing restrained shrinkage and thereby need to be taken into account in the identifi- cation of performance criteria for dimensional compatibility.

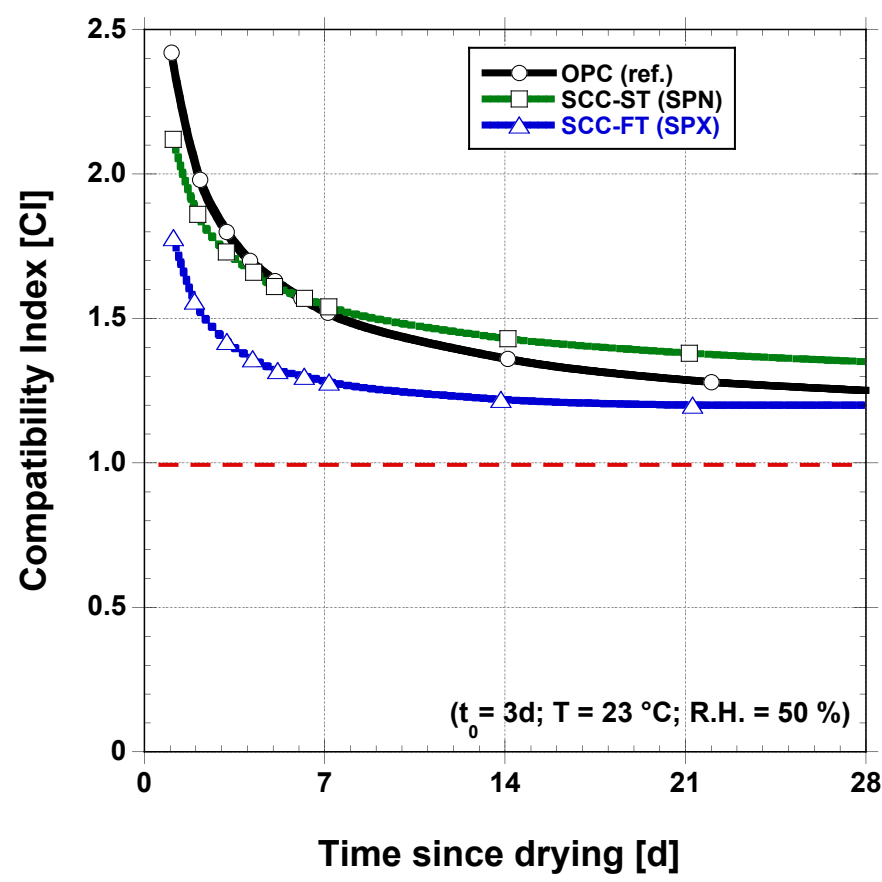

Figure 4. Evolution of the compatibility index (CI value) with time for a reference repair concrete (OPC) and two selfcompacting repair concrete mixtures prepared with a slagbased ternary cement (SCC-ST) and a fly ash-based ternary binder (SCC-FT), exposed to drying at $50 \%$ R.H. at the age of 3 days.

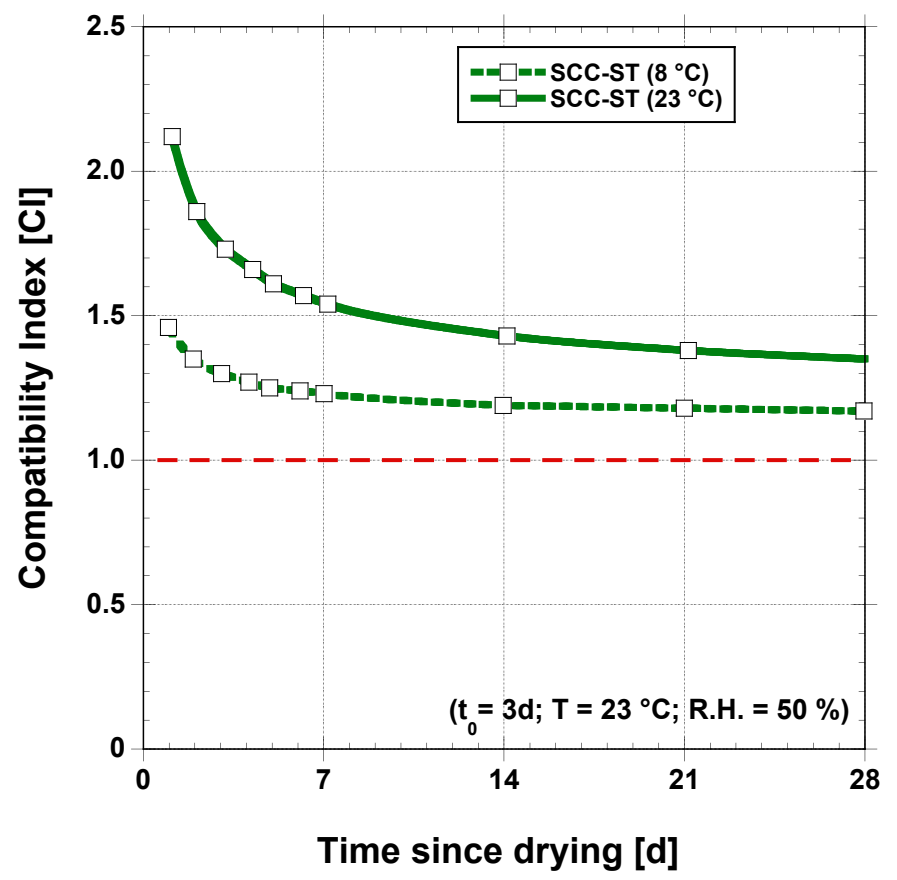

Figure 5. Evolution of the compatibility index (CI value) with time for a self-compacting repair concrete mixtures prepared with a slag-based ternary cement (SCC-ST) and, exposed to drying at $50 \%$ R.H. at different temperatures, starting from the age of 3 days. 
Further investigations will address the identification of performance criteria, based on the CI approach, as well as the possibility to extract all the relevant information with a limited amount of tests (e.g. mechanical properties, length change and ring tests).

\section{CONCLUSION}

The proposed compatibility index appears as a quite promising analytical tool for predicting the performance of repair materials in terms of shrinkagecracking resistance. Compatibility index data were determined for a range of repair materials and confronted with ring test results. The comparison showed good correlation, the mixture classification determined on the basis of compatibility index calculations being consistent with the classification based on the shrinkage-induced stresses recorded experimentally.

The compatibility index provides a sound basis for the identification of dimensional compatibility criteria. Such performance criteria are much awaited in the repair industry, to assist both the development of crack-resistant materials and the issuance of improved materials specifications.

\section{ACKNOWLEDGMENTS}

This project has been financially supported by the Concrete Research Council of the American Concrete Institute (ACI), the Natural Sciences and Engineering Research Council of Canada (NSERC), the Québec FR-QNT Research Fund, and the industrial partners of the NSERC Industrial Chair on Durable Repair and Optimized Maintenance of Concrete Infrastructures at Laval University (BASF Building Systems, City of Montreal, City of Québec, Euclid, Holcim, Hydro-Québec, Kerneos, King Packaged Materials, Lafarge, Ministry of Transportation of Québec, W.R. Grace \& Co.), and through Scientific Cooperation Programs of the Polish, Québec and Wallonia-Brussels governments.

\section{REFERENCES}

AASHTO PP34. 2005. Standard practice for estimating the cracking tendency of concrete, American Association of State and Highway Transportation Officials, Washington, DC, 5 p.

ASTM C1581. 2009. Standard test method for determining age at cracking and induced tensile stress characteristics of mortar and concrete under restrained shrinkage, Annual Book of ASTM Standards, Concrete and aggregates, volume 04.02, ASTM, West Conshohocken, PA, USA, 7 p.

Cusson, D. 1995. Durable concrete patches, Construction Canada, 37(4), pp. 34-39.

Emberson, N.K. \& Mays, G.C. 1990. Significance of property mismatch in the patch repair of structural concrete - part 1: properties of repair systems, Magazine of Concrete Research, 42(152), pp. 147-160.

Emmons, P.H. \& Vaysburd, A.M. 1993. Compatibility considerations for durable concrete repairs, Transportation Research Record 1382, pp. 13-19.

Emmons, P.H. \& Vaysburd, A.M. 1995. Performance criteria for concrete repair materials - Phase I, U.S. Army Corps of Engineers, Technical Report REMR-CS-47, Washington (DC), April, 123 p.

Emmons, P.H.; Vaysburd, A.M.; McDonald, J.E.; Poston, R.W. and Kesner, K.E. 1993. Selecting durable repair materials: performance criteria, Concrete International, 22(3), pp. $38-45$.

Hossain, A.B. \& Weiss, J. 2006. The role of specimen geometry and boundary conditions on stress development and cracking in the restrained ring test, Cement and Concrete Research, 36(1): p. 189-199.

Marosszeky, M. 1992. Stress performance in concrete repairs, International Conference on Rehabilitation of Concrete Structures, Melbourne, pp. 467-474.

Modjabi-Sangnier, F. 2010 Approche quantitative de la notion de compatibilité des bétons de réparation autoplaçants (Quantitative approach of the compatibility concept applied to self-compacting repair concretes), $P h D$ thesis, Laval University, $240 \mathrm{p}$.

(url: http://www.theses.ulaval.ca/2010/27477/)

Morency, M.; Vaysburd, A.M.; von Fay, K.F. and Bissonnette, B. 2005. Development of a test method to evaluate cracking tendency of repair materials - CREEP Phase I Report, Research Report 2004-1, U.S. Bureau of Reclamation, Denver (CO), USA, March.

Morgan, D.R. 1996. Compatibility of concrete repair materials and systems, Construction and Building Materials, 10(1), pp. 57-67.

Pigeon, M. \& Bissonnette, B. 1999. Tensile creep and cracking potential of bonded concrete repairs, Concrete International, 21(11), pp. 31-35.

Pigeon, M. \& Saucier, F. 1992. Durability of repaired concrete structures, Advances in Concrete Technology, ed. V.M. Malhotra, pp. 741-773.

Plum, D.R. 1990. The behavior of polymer materials on concrete repair and factors influencing selection, The structural engineer, 68(17), pp. 337-345.

See, H.T.; Attiogbe, E.K.; Miltenberger, M.A. 2003. Shrinkage cracking characteristics of concrete using ring specimens, ACI Materials Journal, 100(3), pp. 239-245.

Vaysburd, A.M.; Bissonnette, B. \& von Fay, K.F. 2015. Compatibility issues in design and implementation of concrete repairs and overlays, Report No. MERL-2014-87, Bureau of Reclamation, U.S. Department of Interior. 134. 